\title{
Spatial and Technological Periphery of Types of Economic Activity and Regions in Transition to Sustainable Development
}

\author{
Sergey Kukushkin ${ }^{1}$, Oleg Kalenov ${ }^{2,}$, Raisa Kamanina ${ }^{3}$, and Olga Kosareva ${ }^{3}$ \\ ${ }^{1}$ Plekhanov Russian University of Economics, Academic Department of Organizational and \\ Managerial Innovations, 117997, Moscow, 36 Stremyanny lane, Russia \\ ${ }^{2}$ Plekhanov Russian University of Economics, Academic Department of Industrial Economics, \\ 117997, Moscow, 36 Stremyanny lane, Russia \\ ${ }^{3}$ Moscow University for Industry and Finance «Synergy», Academic Department of Commerce and \\ Trade, 129090, Moscow, 9/14 Meshchanskaya street, Russia
}

\begin{abstract}
Currently, the economic development of an industry or type of activity cannot be considered in isolation from the spatial component. Any organization is located in some territory. It has to interact not only with suppliers and consumers, but also with the population that lives in this territory. Therefore, the economic efficiency of the activities of any organization is directly related to the social-and-economic situation of a particular space, territory. The regions in which mining enterprises are located and systemically important are no exception. These organizations belong to the "technological periphery". New technological solutions, which are the core of economic development for new industries and some of the traditional industries, come here with a delay. Moreover, for many of their consumers, their products are not in demand. And the consequence of this is not only the economic problems of the enterprise, but also the social problems of the region or settlement. The article considers the problem of functioning for these enterprises and regions in the conditions of a new technological structure.
\end{abstract}

\section{Introduction}

When the term "periphery" is considered, it is assumed that there is a pair antinomy "center / core - periphery". In economic science, the category of "periphery" is most often used as one of the characteristics of space. These antonyms are usually used in disciplines that describe social and political processes.

Basic economic theories, starting from the 19th century, did not pay enough attention to the spatial characteristics of economic processes. An exception is the "model of an isolated state" of the German thinker of the beginning of the 19th century I von Thunen [1]. In it he considers the city, which is the center of sales of goods produced by agricultural enterprises - farms, as the "core". Therefore, according to his model, the price of products includes not only the costs of the manufacturer itself, but also transportation costs. Comparing

\footnotetext{
* correspondent author: oekalenov@yandex.ru
} 
transportation costs and using differential measurements, I. von Thunen calculated the effective sales zones for agricultural products.

The classical economic theory, like the Marxist one, recognized that the allocation of resources affects the amount of transport costs, and, consequently, the total costs, but in their opinion, this is not a determining factor affecting the size of natural rent [2].

\section{Materials and Methods}

The attitude of economic thought to the concept of periphery changed in the second half of the 20th century, when the colonial system of many leading in economy countries began to disintegrate, and under the influence of this a new world economic order began to take shape. It was that time when the Argentine economist Raul Prebisch [3] developed the concept of periphery.

The starting point of this concept was the importance of "structural" factors, which led to "economic backwardness." In his work, R. Prebish argued that the countries of the third world - the periphery, mainly act as suppliers of natural resources for the metropolitan countries, and more developed countries - the "core". At the same time, the terms of trade between the countries of the periphery and the countries of the "core" in the long-term tend to worsen. Based on this, he drew two conclusions that form a "vicious circle" for peripheral countries:

- there is a "vicious circle" that does not allow these countries to narrow the gap in the productivity and standard of savings levels with industrialized countries - the "core";

- peripheral countries cannot take advantage of productivity growth that can be achieved in the national economy.

Later, in the $1960 \mathrm{~s}$, based on the stated thesis, the doctrine of "dependista" arose, focusing on the dependent position of peripheral countries in the system of economic relations. On the ground of this, a "theory of modernism" or "developmentalism" was developed.

Developmentism considers how peripheral countries can participate in the development process. Any country can move along the development trajectory taking into account its national and historical features, thereby providing itself with the necessary combination of characteristics. One of the most influential works revealing this theory was the work of W. Rostow's "Stages of Economic Growth" [4].

In his work, W. Rostow identifies six stages of growth (Figure 1):

1) traditional society - a large part of the population (more than $75 \%$ ) produces food; power belongs to landowners and / or government officials; national income is used inefficiently; there is an estate-hierarchical structure of society;

2) transition to takeoff; changes occur in the non-industrial sectors of the national economy: agriculture, transport, foreign trade;

3) take-off - an increase in the rate of investment, an increase in the average per capita output, the introduction and application of new technologies in industry and agriculture. Initially, development affects a narrow group of industries, and then these processes smoothly cover the entire national economy.

Economic growth is possible if the following prerequisites are met:

- the share of investments in manufacturing industries should be from $5 \%$ to $10 \%$;

- the development of one or more industries;

- political power in society belongs to the supporters of modernization.

The time period of this stage is from 20 to 30 years.

4) moving towards maturity - the development of a long stage of scientific and technological progress. During this period, urbanization develops, labor becomes more qualified, business and society are managed by professional managers; 
5) the age of mass consumption - a shift from supply to demand, from production to consumption;

6) search for quality of life - there is a spiritual development of a person, the development of an information society.

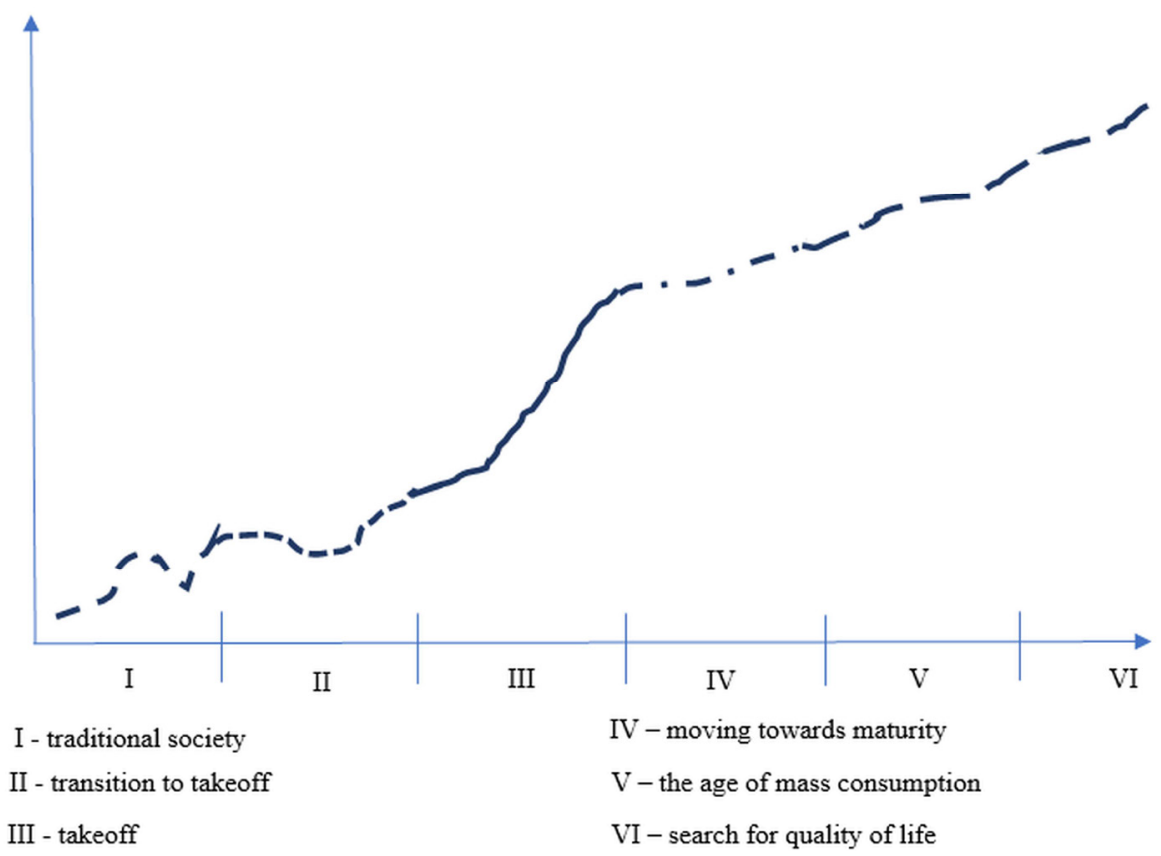

Fig. 1. The stages of economic growth.

The theory of modernism ("developmentalism") is applicable in economic policymaking for the development of Russian regions, especially those regions in which extractive industry enterprises are strategic organizations.

\section{Results and Discussion}

The territory of Russia is more than 17 million $\mathrm{km}^{2}$ (without water surface); therefore, its many regions have distinctive characteristics in comparison with each other. This is due to the fact that Russia is located in several geographical areas that are different in their climatic conditions and are not quite comfortable for the population to live. Therefore, the population density is different. Somewhere we observe a large population, the consequence of this is a lack of jobs and an excess of labor. In other areas, the situation is vise a versa.

Sources of raw materials and minerals are also uneven. Therefore, those regions where there are popular sources of mineral resources, especially liquid and gaseous hydrocarbons, are more economically and socially safe [5].

An opposite situation is in the regions where there are or were deposits of solid hydrocarbon raw materials - coal and brown coal. Therefore, for example, in Soviet times on the territory of the Rostov region there were two of the largest coal mining production enterprises. Social and economic reforms in Russia, as well as the price situation on the world market, led to the fact that these enterprises became unprofitable and mines began to close. This also entailed social consequences - rising unemployment, aging population, relocation of residents to other settlements and areas, etc. [6] 
There are also still undeveloped areas - the territory of Eastern Siberia - in Russia. Large mineral deposits have been explored and proved there, but their industrial development is delayed for the technological and transport reasons [7].

Another feature of the Russian regions is historically cultural diversity. More than 100 peoples and nationalities live in the Russian regions; each of them has its own history, culture and are at different stages of social development.

The development of regions has left its mark on industrial policy of past periods. When Soviet industry was created, processing enterprises were located in close proximity to sources of mineral raw materials. If we consider this solution in the medium term, it was effective. This was determined by significant savings in transportation costs of mineral raw materials and the relative cheapness of production. Over time, sources of raw materials were depleted or their extraction became very expensive for reasons beyond humans control. However, processing capacities remained, and now, to ensure their loading, raw materials are transported from other areas. Thus, the transport component becomes decisive in the price of future products derived from this raw material. This leads to the fact that the processing enterprises lose or do not make a part of (past) profit, which affects their economic situation, and, consequently, their social situation. To reduce the costs of manufactured products, they are forced to cut back on their social infrastructure, which invariably affects the social situation in the region or locality.

The transport component also influenced the marketing of products made from minerals. Previously, in the immediate vicinity of sources of raw materials and processing facilities, consumers were located. This led to the concentration of labor in certain areas and caused its decline from other areas.

Today, consumers are located at a considerable distance from manufacturers of materials, due to the following reasons:

- social-and-economic policy of the former leadership of the country: the desire to ensure the uniform development of all regions, the formation and creation of types of economic activity in their territories that are not traditional in historical-cultural and naturalgeographical conditions;

- as a result of the development of scientific and technological progress, new types of materials have appeared that allow obtaining other characteristics for the final product [8]; - there is a transformation of factors of production. The classical ones - labor and capital become the conditions of production, and knowledge becomes the factor of production. As a result, both producers and consumers are concentrated in close proximity to centers of knowledge development.

As for the extractive industries, which are systemically important for some regions, they experience similar problems. Being at the very beginning of the technological chain of creating final consumer goods, they are deprived of the advantages that organizations producing final products have. In other words, they do not receive the added value that manufacturers receive, which are in the subsequent stages of production the consumer goods.

At the same time, they are far from organizations that develop and apply new, advanced technologies. New technological solutions come to them after some time. Moreover, new technological organizations often do not feel the need for products of traditional extractive industries [9].

That is, it turns out that the mining enterprises are located away from the technological core, which is the basis of the new technological structure (the structure of technological layer is shown in Figure 2).

What is the solution to this problem? 


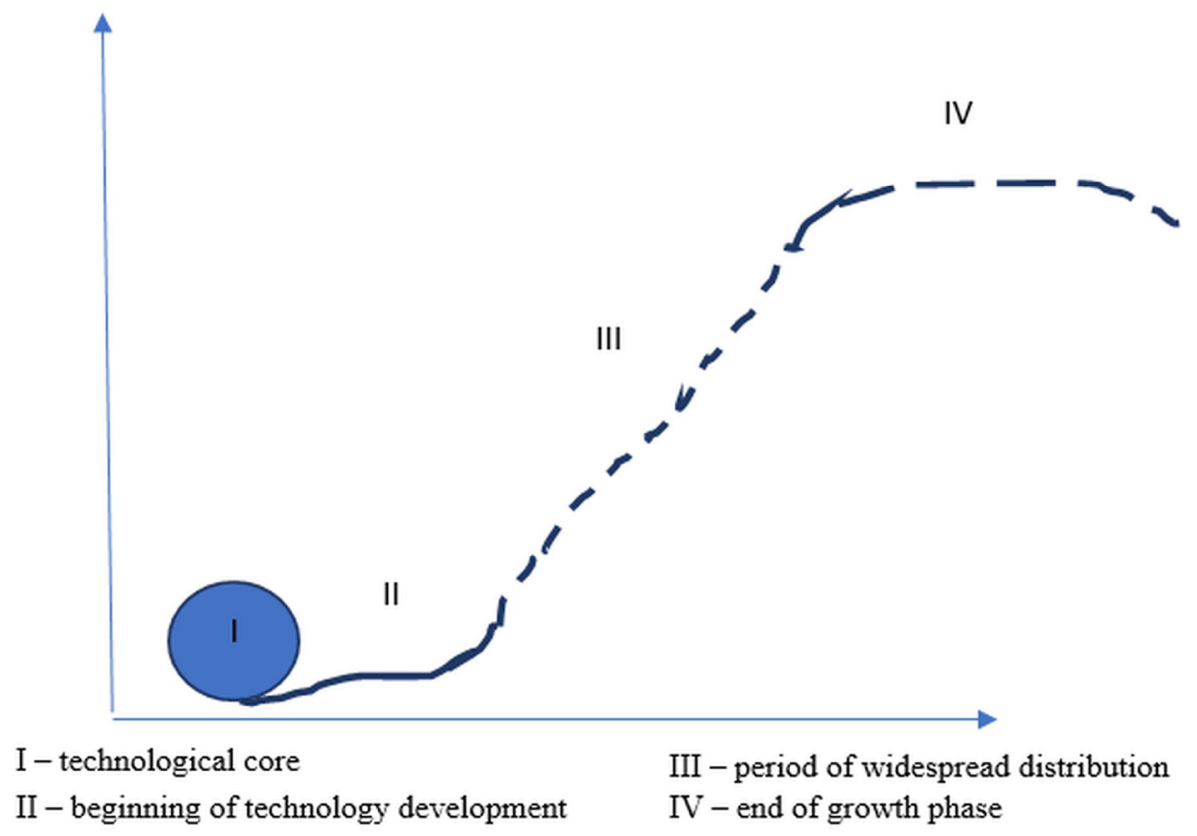

Fig. 2. The structure of technological layer [10].

As evidenced by the historical and economic experience of many countries, the development of new territories [11], and with them the territories where mining is strategic, is possible on a different technological platform [12].

Technological solutions of the V (information technology) and VI structure (nanotechnological) technological layers provide such opportunities. Information technology is able to provide the connections and communications that are so necessary for obtaining knowledge and information not only for producers, but also for consumers. Thanks to them, the source of knowledge (information) and their recipient (consumer) can be located at a considerable distance from each other, but, despite this, knowledge will come in real time and in the required volume. Information technology can also solve a social problem: any resident of a remote area will not feel like a provincial, being on the periphery.

Significant potential lies in nanotechnologies, which are an important component of convergent technologies or NBIC convergence [13]. The concept of NBIC-convergence was put forward in 2002 in a report to the World Technology Evaluation Center (WTEC). The NBIC concept was a logical continuation of the nanotechnology development program adopted by the B. Clinton administration in 1996.

Of the four technologies presented, the most developed is information technology, which is currently being transformed into information and communication technology (ICT). ICT serves as a link between other technologies, creating and supplying tools for the development of other areas of knowledge and technology. For example, today, using this ICT, we can simulate complex processes, thereby saving time and resources.

Great potential lies in nanotechnology. Their development and further use allows creating new materials with desired properties, developing new energy sources, etc. The use of nanotechnology will lead to a change in the structure of both individual business organizations and the national economy $[14,15]$.

The third in this "group" is biotechnology, which is also capable of providing a broad basis for the development of ICT and nanotechnology. Already today, the interaction of nano- and biotechnologies is visible. Biotechnologies have contributed to the construction 
and development of some nanostructures, for example, they created special DNA sequences. They are very widely used to create various prostheses that can replace or restore human organs. In general, according to some scientists, the interaction of nano- and biotechnologies is able to form a new industry in medicine - nanomedicine.

The fourth in this "group" - cognitive technology - is quite far from the first three. This is due to the fact that there is not enough knowledge, and therefore the possibilities of interaction with other technologies are still limited. One of the reasons is that cognitive science (also called "the science of mind"), along with nanotechnology, began to develop relatively recently. In the future, nanotechnology will be able to provide tools for scanning the brain and its computer simulation. This will provide the necessary depth and scanning for analysis and study of this object.

\section{Conclusion}

What is the practical solution to this problem? What should be the vector of state and regional social-and-economic policies to address the problems of regions in which extractive industry enterprises are strategically important? Today, the products of mining enterprises may become sources for new nanomaterials. The creation and implementation of nanotechnology can take place in centers in which new knowledge is being formed. However, it is not enough just to form new knowledge and show its commercial perspective. It is necessary to ensure their effective implementation and application. Technological parks and technopolises can become, and in many cases already are, such organizational centers. These structures have not only experience and means for introducing and using new technical and technological solutions, but, just as importantly, they have desire and energy.

\section{References}

1. I. Thunen, Isolated State (Economic life, Moscow, 1926)

2. O. Ivanenko, E3S Web Conf., 105, 04025 (2019)

3. R. Prebich, The Economic Development of Latin America and Its Principal Problems (United Nations, New York 1950)

4. W.W. Rostow, The Stages of Economic Growth (Cambridge University Press, New York-London, 1960)

5. A. Balabanova, V. Balabanov, E. Dotsenko, N. Ezdina, E3S Web Conf., 15, 04013 (2017)

6. O. Borisova, V. Frolova, L. Artamonova, E3S Web Conf., 105, 04047 (2019)

7. V. Frolova, O. Dolina, T. Shpilkina, E3S Web Conf., 105, 01054 (2019)

8. M. Anastasov, N. Kazitskaya, I. Politkovskaya, E3S Web Conf., 105, 04043 (2019)

9. O. Miliushenko, A. Kovalev, M. Zhidkova, E3S Web Conf., 105, 04046 (2019)

10. S. Yu. Glazyev, The Theory of Long-Term Technical and Economic Development (VlaDar, Moscow, 1993)

11. L. G. Badalyan, V.F. Krivorotov, History. Crises. Prospects: a new look at the past and future (Book House, Moscow, 2012)

12. F. Agafonov, A. Genin, O. Kalinina, O. Brel , O. Zhironkina, E3S Web Conf., 15, 04011 (2017)

13. E. Dotsenko, E3S Web Conf., 21, 04013 (2017) 
14. E. Shavina, S. Fisunov, E3S Web Conf., 105, 04018 (2019)

15. E. Shavina, N. Moiseev, E. Dotsenko, A. Sivkova, Espacios, 41:03, 20 (2020) 